\title{
Grávidas fumadoras: uma prioridade e um desafio para os médicos de família
}

Luís Rebelo*

\section{O PROBLEMA}

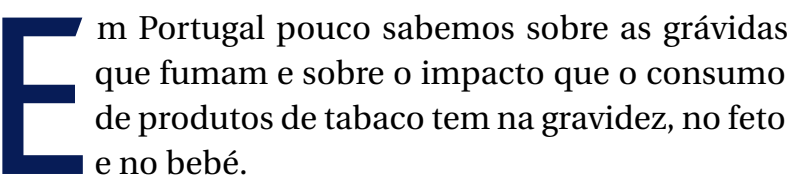

Mas, não existe dúvida, de que o impacto existe e é grave. $\mathrm{O}$ tabagismo ativo materno durante a gravidez afeta negativamente o peso da criança à nascença e aumenta os riscos de aborto espontâneo, gravidez ectópica, descolamento prematuro da placenta, parto prematuro, restrição de crescimento intrauterino, anomalias congénitas e distúrbios respiratórios. ${ }^{1}$

Nos EUA, nos últimos 50 anos, mais de 100.000 mortes causadas pelo tabaco foram de bebés que morreram de síndroma de morte súbita infantil ou outras condições de saúde relacionadas com o tabaco.Apesar de ter reduzido nas últimas décadas, anualmente mais de 400.000 fetos nos EUA são expostos in útero ao tabaco. ${ }^{2}$

Segundo dados do Public Health London, fumar durante a gravidez causa anualmente no Reino Unido 2.200 partos pré-termo, 5.000 abortos e 300 mortes no período perinatal. ${ }^{3}$

Grávidas que fumam na gravidez têm o dobro das hipóteses de terem um bebé com baixo peso ao nascer. Esta é uma das conclusões da revisão sistemática da literatura realizada por Silva Pereira e colaboradores. Também concluiu que fumar durante a gravidez é um dos fatores de risco modificáveis mais importantes de impacto negativo no crescimento fetal e no seu desenvolvimento. ${ }^{1}$

Em Portugal, em 2017, 8,9\% das crianças nascidas registavam baixo peso à nascença (peso inferior a 2.500 gramas), valor comparável com os $6,5 \%$ de média na OCDE e superado apenas pela Grécia, Chipre e Bulgá-

*Médico de Família.

Responsável do Programa de Prevenção e Controlo do Tabagismo (PPCT) da ARSLVT. Consulta de Apoio Intensivo de Cessação Tabágica. ria, o que representa um aumento de $60 \%$ entre 1990 e 2015. ${ }^{4}$

A prevalência de consumo ativo de tabaco nas mulheres grávidas foi estimada até $25 \%$ em todo o mundo. ${ }^{1}$

Em Portugal, de acordo com Alves e colaboradores, que estudaram uma amostra de grávidas de cinco maternidades do Porto em 2005-2006 e as seguiram durante quatro anos, obtiveram-se os seguintes resultados: $22,9 \%$ de grávidas a fumarem antes da gravidez, $47,4 \%$ pararam de fumar ao saberem que estavam grávidas, $41,7 \%$ reduziu durante a gravidez, $11 \%$ mantevese a fumar e $33 \%$ voltaram a fumar depois do parto. Quanto mais cigarros e menos escolaridade menos pararam de fumar. ${ }^{5}$

Ainda, segundo o estudo do SICAD, numa amostra representativa obtida nos cuidados de saúde primários, antes de engravidar $27,7 \%$ das mulheres fumava tabaco, 13,8\% já não fumava quando tiveram conhecimento da gravidez e $58,5 \%$ nunca tinham fumado tabaco na vida; $17 \%$ fumaram tabaco durante a gravidez; ainda, $15,6 \%$ reduziram o número de cigarros fumados quando tomaram conhecimento da gravidez. Nas grávidas que mantiveram o nível de consumo, a mediana era de 15 cigarros/dia. ${ }^{6}$

\section{A INTERVENÇÃO}

Identificação, antes de mais. Identificar e registar. É necessário que os médicos identifiquem as grávidas, 0 que sempre fazem ao iniciarem a vigilância de uma gravidez, e que identifiquem os consumidores de produtos do tabaco, registando no mínimo o número de cigarros/dia e os anos de consumo. Ambos os diagnósticos devem ter por base os códigos do ICPC2. Estima-se que um médico de família, com uma lista de utentes aproximadamente de 1.750 utentes, com 10 a 20 grávidas por ano, possa ter entre duas a cinco grávidas fumadoras. 
Como e quando intervir? As recomendações internacionais são muito claras. Por exemplo, a USPSTF recomenda aos clínicos que inquiram todas as grávidas sobre os seus hábitos tabágicos, aconselhando-as a pararem de fumar, e que realizem intervenções comportamentais nas que fumam. A evidência é de tipo A. ${ }^{7} \mathrm{O}$ tipo de intervenção a usar é a «Intervenção Breve» que usa, como metodologia, os 5As e os 5Rs que devem ser adaptados na grávida. ${ }^{8-9}$

A OMS propõe segmentar as mulheres grávidas ao intervir de acordo com a fase em que se encontram em relação ao consumo de produtos de tabaco. A mulher fumadora não grávida justifica a intervenção por todos os profissionais que com ela contactam, seja na consulta de adultos ou pré-concecional. A grávida, que deixou de fumar logo que soube que estava grávida, deve ser avaliada durante toda a gravidez até, pelo menos, aos dois meses depois do parto. As que passam a gravidez a fumar, tenham reduzido ou não o número de cigarros, têm indicação para intervenções breves ou intensivas, de acordo com o seu nível de dependência e de sintomas de privação. Nas que recaem, há que voltar a percorrer todas as etapas dos 5As e 5Rs. ${ }^{10}$

\section{O COMPROMISSO}

Sabemos que esta temática, embora importante e pertinente, ainda não consta das formações pré e pósgraduada. É urgente colmatar a falha. O treino específico dos profissionais é necessário. Monitorizar o cumprimento dos indicadores aplicáveis e integrá-los no Îndice Global de Desempenho (IDG) é indispensável. Criar incentivos para as mulheres grávidas deixarem de fumar e alertá-las para os riscos que correm e os benefícios que podem vir a ter a curto prazo é urgente. Necessitamos de mais materiais específicos de apoio à intervenção e de expandir as campanhas nos media.
Os profissionais dos cuidados de saúde primários têm uma palavra a dizer, por serem quem são e por fazerem o que fazem.

Para minorar este sério problema de saúde em Portugal é necessário um compromisso conjunto de todos os atores que para o mesmo podem contribuir. Assim haja vontade.

\section{REFERÊNCIAS BIBLIOGRÁFICAS}

1. Pereira PP, Mata FA, Figueiredo AC, Andrade KR, Pereira MG. Maternal active smoking during pregnancy and low birth weight in the Americas: a systematic review and meta-analysis. Nicotine Tob Res. 2017;19(5):497-505. doi:10.1093/ntr/ntw228

2. National Center for Chronic Disease Prevention and Health Promotion, Office on Smoking and Health. The health consequences of smoking: 50 years of progress (a report of the Surgeon General). Atlanta, GA: Centers for Disease Control and Prevention; 2014.

3. Department of Health. Towards a smokefree generation: a tobacco control plan for England. London: Department of Health; 2017.

4. OECD. Health at a glance 2017. Paris: OECD; 2017.

5. Alves E, Azevedo A, Correia S, Barros H. Long-term maintenance of smoking cessation in pregnancy: an analysis of the birth cohort generation XXI. Nicotine Tob Res. 2013;15(9):1598-607. doi:10.1093/ntr/ntt026

6. Serviço de Intervenção nos Comportamentos Aditivos e nas Dependências. O consumo de álcool na gravidez. Lisboa: SICAD; 2015.

7. U.S. Preventive Services, Task Force. Tobacco smoking cessation in adults, including pregnant women: behavioral and pharmacotherapy interventions [homepage]. Rockville, MD: U.S. Preventive Services; 2015 Sep. Available from: https://www.uspreventiveservicestaskforce.org/Page/ Document/UpdateSummaryFinal/tobacco-use-in-adults-and-pregnant-women-counseling-and-interventions 1

8. Direção-Geral da Saúde. Cessação tabágica na gravidez: guia para profissionais de saúde. Lisboa: DGS; 2015. ISBN 9789726751991

9. Rebelo L, editor. Cessação tabágica. Coimbra: Almedina; 2019. ISBN 9789724079219

10. World Health Organization. Pregnancy and pospartum smoking cessation. In: WHO. Gender, women, and the tobacco epidemic. Geneva: WHO; 2010. p. 175-88. ISBN 9789241599511

\section{ENDEREÇO PARA CORRESPONDÊNCIA}

E-mail: Irebelo@sapo.pt 